\title{
Seven days in medicine: 21-27 November
}

Clarification-We would like to point out that the model of the blood vessels in the lungs used to illustrate the news item (BMJ 2015;351:h6335, doi:10.1136/bmj.h6335) on the Designing Bodies exhibition at the Hunterian Museum was designed by David Hugh Tompsett. Martyn Cooke designed models of the brain and skull that are included in the exhibition. Also included are models by the orthopaedic surgeon John Hicks of the lower leg and foot, which were used to improve treatments for patients with leg injuries in the 1950s and 1960s.

Cite this as: BMJ 2015;351:h6454

๑ BMJ Publishing Group Ltd 2015 